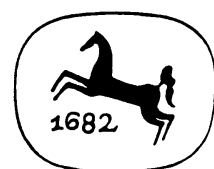

Sammlung Metzler

Band 223 
Frank Dietschreit

Barbara Heinze-Dietschreit

\section{Hans Magnus Enzensberger}

J.B. Metzlersche Verlagsbuchhandlung

Stuttgart 
CIP-Kurztitelaufnahme der Deutschen Bibliothek

Dietschreit, Frank:

Hans Magnus Enzensberger /

Frank Dietschreit; Barbara Heinze-Dietschreit. Stuttgart: Metzler, 1986.

(Sammlung Metzler; M 223: Abt. D, Literaturgeschichte)

NE: Heinze-Dietschreit, Barbara; GT

ISSN 0558-3667

ISBN 978-3-476-10223-2

ISBN 978-3-476-03927-9 (eBook)

DOI 10.1007/978-3-476-03927-9

M 223

(C) 1986 Springer-Verlag GmbH Deutschland Ursprünglich erschienen bei J. B. Metzlersche Verlagsbuchhandlung und Carl Ernst Poeschel Verlag GmbH in Stuttgart 1986 
Anstelle einer Einleitung. Der romantische Zeitgenosse:

Enzensberger und Clemens Brentano. . . . . . . . .

\section{Lyrische Virtuosität und politisch-literarisches}

Widerspruchsprogramm (1955-1965)

1. Stichworte zum politisch-kulturellen Kontext . . . . . . . 9

2. Das literarische Werk, Editionen und Essays (1955-1965) . . . . 13

2.1. verteidigung der wölfe (1957) . . . . . . . . . . . . . 13

2.2. landessprache $(1960) \ldots \ldots \ldots \ldots \ldots \ldots \ldots . \ldots \ldots$

2.3. blindenschrift $(1964) \ldots \ldots \ldots \ldots \ldots \ldots \ldots . \ldots \ldots$

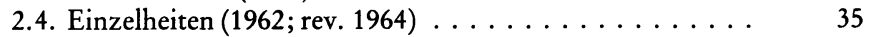

2.4.1. Poesie und Politik. . . . . . . . . . . . . . . . . 37

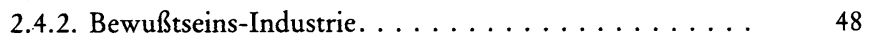

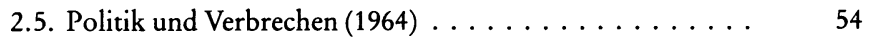

II Politisierung und Dokumentarismus: Strategien gegen die Harmlosigkeit der Literatur (1965-1975)

1. Stichworte zum politisch-kulturellen Kontext . . . . . . . 59

1.1. Politisierung von Gesellschaft und Literatur . . . . . . $\quad 59$

1.2. Kursbuch - Eine neue Zeitschrift. . . . . . . . . 61

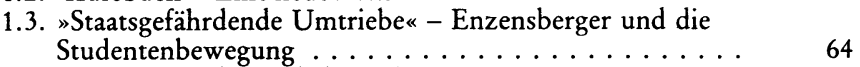

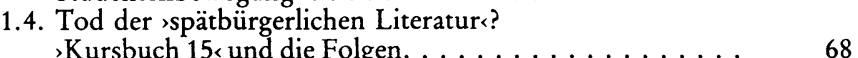

2. Das literarische Werk, Editionen und Essays (1965-1975) . . . . 73

2.1. Der Hessische Landbote (1965) . . . . . . . . . . . . 77

2.2. Las Casas oder Ein Rückblick in die Zukunft (1966) . . . . . 78

2.3. Schiller: Gedichte (1966) . . . . . . . . . . . . . . . 79

2.4. Freisprüche. Revolutionäre vor Gericht (1970) . . . . . . . 80

2.5. Das Verhör von Habana (1970) . . . . . . . . . . . . . . 82

2.6. Gedichte 1955-1970 (1971) . . . . . . . . . . . . . . 88

2.7. Der kurze Sommer der Anarchie (1972) . . . . . . . . 92

2.8. Klassenbuch (1972) . . . . . . . . . . . . . . . 97

2.9. Gespräche mit Marx und Engels (1973) . . . . . . . . . . 98

2.10. Der Weg ins Freie (1975) . . . . . . . . . . . . 100

III Biographie, Gesang und Bübne: Die Rückkebr zu den leisen Tönen der literarischen Mitteilungsformen (1975-1985)

1. Stichworte zum politisch-kulturellen Kontext . . . . . . . 102

2. Das literarische Werk, Editionen und Essays (1975-1985) . . . . 106

2.1. Mausoleum (1975). . . . . . . . . . . . . . 108 
2.2. Der Untergang der Titanic (1978) . . . . . . . . . . . 115

2.3. Der Abendstern (1979) und Die Furien des Verschwindens (1980) . . . . . . . . . . . . . . 125

2.4. Die >Politischen Brosamen $<$ der >TransAtlantik « . . . . . . 129

2.5. Molières Menschenfeind (1979) . . . . . . . . . . . . . . . . 135

2.6. Der Menschenfreund (1984) . . . . . . . . . . . . 139

2.7. Die Andere Bibliothek (1985). . . . . . . . . . . . 142

\section{Literaturverzeichnis}

1. Primärliteratur Enzensberger

1.1. Selbständige Veröffentlichungen, Sammlungen . . . . . . . 148

1.2. Beiträge zu Zeitschriften, Zeitungen, Sammlungen . . . . . 149

1.3. Editionen, Nachworte . . . . . . . . . . . . . . . . . 153

1.4. Übersetzungen. . . . . . . . . . . . . . . . . . . . . . . . . . . . 154

1.5. Rundfunk, Fernsehen . . . . . . . . . . . . . . . . . . . 154

2. Sekundärliteratur .................... 155

Register....................... 170 
In unserer Absicht liegt es nicht, das Werk des Literaten und Publizisten Hans Magnus Enzensberger aus dessen persönlicher Geschichte zu erklären. Wer an einer Zusammenschau biographischer Daten interessiert ist, sei auf die mit einer gewissen Monotonie wiederholt abgedruckte Vita Enzensbergers in seinen bei Suhrkamp erscheinenden Büchern verwiesen, auf die auch wir uns in gebotener Kürze beziehen. Es geht uns vielmehr darum, das kaum mehr zu überschauende literarische, essayistische und publizistische Werk Enzensbergers in seinen grundsätzlichen Aspekten und Linien zu rekonstruieren. Bei einem Schriftsteller, der sich, wie nur wenige andere, in die Politik einmischt bzw. stets auf politische Wirkungen zielt, war es angebracht, das Werk im jeweils spezifisch politisch-kulturellen Kontext zu lesen. Angesichts der Platznot mußten wir uns dabei allerdings mit Andeutungen begnügen.

Begnügen mußten wir uns auch mit der Sichtung der Rezeption der Werke Enzensbergers im deutschen Sprachraum. Bis auf wenige Ausnahmen wurde darauf verzichtet, die Aufnahme der im Ausland erschienenen Publikationen kritisch zu sondieren. Einen Einblick sowohl in das vielfältige Schaffen Enzensbergers als auch in die in- und ausländische Rezeption gibt die Bibliographie Alfred Estermanns. Sie umfaßt 1693 Belege und kann - für den Zeitraum von 1955 bis 1983 - als fast lückenlos angesehen werden. Mit ihr zu konkurrieren liegt uns fern. Einer späteren Auflage dieses Buches sei allerdings eine Fortschreibung der Bibliographie vorbehalten.

Literaturwissenschaftliche Betrachtung konzentriert sich zumeist auf einsehbare Buchpublikationen. Das erweist sich im Falle Enzensbergers als unzureichend, da er einen großen Teil seiner schriftstellerischen Potenz dem Hörfunk gewidmet hat. Allein der Süddeutsche Rundfunk (der sich als einzige Rundfunkanstalt unserem Projekt gegenüber wirklich kooperativ zeigte) verzeichnet im Zeitraum von 1954 bis 198456 Radioarbeiten Enzensbergers. $\mathrm{Da}$ wir uns auf einige wenige Hinweise beschränken, bleibt die gründliche Sichtung dieser bisher noch nicht einmal hinlänglich biographisch erfaßten Arbeiten ein Forschungs-Desiderat.

F. D. \& B. H.-D. im September 1985 
1929 Geboren in Kaufbeuren im bayerischen Allgäu. Drei jüngere Brüder.

1931-42 Kindheit in Nürnberg.

1942-45 Luftkrieg, Evakuierung; Besuch der Oberschulen in Gunzenhausen und Oettingen.

1946-49 Oberschule in Nördlingen; Abitur.

1949-54 Studium in Erlangen, Freiburg/Br., Hamburg und Paris (Literaturwissenschaft, Sprachen, Philosophie).

1955 Promotion über Clemens Brentanos Poetik.

1955-57 Rundfunkredakteur in Stuttgart; Gastdozent an der Hochschule für Gestaltung in Ulm.

1957 Aufenthalt in den Vereinigten Staaten und in Mexiko. Erste Buchpublikation (verteidigung der wölfe).

1957-59 >Rückzug، als freier Schriftsteller nach Stranda/Norwegen.

1959-60 Italienaufenthalt, Lanuvio bei Rom.

1960-61 Verlagslektor in Frankfurt/M.

1961 Erneuter $>$ Rückzug nach Norwegen (Tjöme)

1963 Büchner-Preis. Erster Aufenthalt in der Sowjetunion.

1964-65 Gastdozent für Poetik an der Frankfurter Universität.

1965 Erste Südamerika-Reise. Umzug nach West-Berlin. Gründung des Kursbuchs.

1967-69 Nach Aufgabe der Fellowship an der Wesleyan University, Connecticut, USA, Reise in den Fernen Osten. Danach längerer Aufenthalt in Kuba.

1970 Gründung des Kursbuch Verlages in Berlin.

1974-75 Längerer Aufenthalt in New York.

1975 Rückzug vom Herausgeber des Kursbuchs zum Mitarbeiter.

1978 Deutscher Kritikerpreis.

1979 Umzug nach München.

1980 Gründung der Zeitschrift TransAtlantik (Mitwirkung bis 1982). Internationaler Preis für Poesie (Struga, Jugoslawien).

1982 Internationaler Pasolini-Preis für Poesie (Rom).

1985 Herausgeber der Anderen Bibliotbek. Kölner Literaturpreis (Heinrich-Böll-Preis). 